\title{
Correlation Between Ankle Brachial Index and Lower Limbs Digital Pulse Oximetry: A Referral Center Experience, Prevalence Study
}

Juan Sanjuan 1, 2, 3, 4 , Edwin Romero ${ }^{3}$, Rolando Medina ${ }^{3}$, Wilmer Botache ${ }^{3}$, Gabriela Ruiz ${ }^{3}$, Andres Ramirez $^{3}$, Estefania Barbosa ${ }^{3}$, Maria Andrade ${ }^{3}$, Roberto Diaz ${ }^{3}$, Francisco J. Montoya ${ }^{5}$

1. Clinical Research, Utopiapp SAS, Cali, COL 2. Clinical Research, Cirugia y Trauma (CYTRA), Universidad Surcolombiana, Neiva, COL 3. Surgery, Universidad Surcolombiana, Neiva, COL 4. Surgery, Hospital Hernando Moncaleano Perdomo, Neiva, COL 5. General Surgery, Universidad Surcolombiana, Neiva, COL

Corresponding author: Juan Sanjuan, drjuansanjuan@gmail.com

\section{Abstract}

Objective

Ankle-brachial index (ABI) is widely recommended and used to evaluate peripheral arterial disease. The oxygen saturation $\left(\mathrm{SpO}_{2}\right)$ has been associated with $\mathrm{ABI}$, showing a promising clinical practice utility; however, little literature regarding this matter has been reported. This study aims to assess the correlation between pulse oximetry and ABI.

Methods

A cross-sectional study was conducted using ABI measuring devices, such as the MESI ${ }^{\circledR}$ Ankle Brachial Pressure Index (ABPI) (MESI, Ltd., Slovenia, EU) and pulse oximetry. We compared the $\mathrm{SpO}_{2}$ distribution by using the Wilcoxon test and evaluated its correlation by using logistic regression.

Results

From a total of 86 patients, 54 were males (62.8\%) and the median age was 54 years old (interquartile range $(I Q R)=37-65$ yrs.). Regarding ABI measurements of the right lower limb (RLL), a total of 20 patients (22.3\%) had an abnormal classification. On the other hand, a total of 21 patients $(22.1 \%)$ had an abnormal classification of the left lower limb (LLL) ABI measurements. The distribution of $\mathrm{SpO}_{2}$ in relation to $\mathrm{ABI}$ categories was not statistically different ( $\mathrm{RLL} p=0.2433$; LLL $\mathrm{p}=0.1242$ ). The $\mathrm{SpO}_{2}$ classification of ABI and abnormal pulse oximetry for the RLL was at $76.7 \%$ and at $77.9 \%$ in the LLL (Pearson's goodness-of-fit test: $\operatorname{RLL}=\mathrm{p}<0.001$ and $\mathrm{LLL}=\mathrm{p}<0.001)$.

Received 11/05/2019

Review began 12/04/2019

Review ended 12/17/2019

Published 01/24/2020

(๑) Copyright 2020

Sanjuan et al. This is an open access article distributed under the terms of the Creative Commons Attribution License CC-BY 3.0 , which permits unrestricted use, distribution, and reproduction in any medium, provided the original author and source are credited.
Conclusion

Although we didn't observe any statistical differences in the $\mathrm{SpO}_{2}$ distribution regarding $\mathrm{ABI}$ measurements, in their correlation, there seems to be a different tendency. The $\mathrm{SpO}_{2}$ might be a useful non-invasive tool to assess asymptomatic patients with risk factors for peripheral arterial disease (PAD).

Categories: Cardiac/Thoracic/Vascular Surgery, Internal Medicine, Preventive Medicine

Keywords: lower limbs, atherosclerosis, ankle-brachial index, peripheral vascular disease

\section{Introduction}

Ankle-brachial index (ABI) is the ratio of the systolic blood pressures of the ankles and arms. It is one of the most useful tests for identifying peripheral arterial disease (PAD) because it can be easily applied, is simple, cheap, and non-invasive. In regard to PAD, the test accuracy is $86 \%-99 \%$ and its sensibility is $75 \%-95 \%$. PAD is often described as a decrease of blood supply to the lower limbs because of an obstruction narrowing the vessel walls, thus reducing blood flow, generally due to atherosclerosis [1-2]. This disease affects over 202 million people worldwide, and it seems to be an independent indicator of cardiovascular morbidity and mortality. Furthermore, it is important for coronary history since patients with PAD showed more risk for both short and long-term coronary artery disease, stroke, myocardial infarction, limb ischemia, and death [3-4]. Although ABI has great prognostic and diagnostic value, it also has several limitations, such as gender, age, calf size, daily stress, sphygmomanometer size, its position, etc. However, it remains an important tool in practice [5-7].

The use of oxygen saturation $\left(\mathrm{SpO}_{2}\right)$ is a common tool used during physical examinations as this non- 
invasive technique is easy and inexpensive to perform [8]. Some experiences describe a certain relationship between pulse oximetry and $\mathrm{ABI}$ in the diagnosis of lower extremity arterial disease [9]. The measurements represent blood flow and $\mathrm{SpO}_{2}$ and are also used as an evaluation after reperfusion injury [9]. In the literature, the $\mathrm{ABI}$ relationship and $\mathrm{SpO}_{2}$ variation of $2 \%-5 \%$ have been suggested as an effective additional method for screening patients with PAD [9-11]. This relationship remains unclear considering the interacting factors [12-13]. Our aim was to assess the correlation between pulse oximetry and ABI in an academic referral hospital setting.

\section{Materials And Methods}

We conducted a cross-sectional study between the months of April and June of 2017 in non-critical care units of an academic referral hospital in South Colombia. A non-probabilistic convenience sample size was considered. Additionally, patients with a blood pressure measurement contraindications were excluded. Throughout this study, we used non-invasive ABI measuring devices, such as the MESI ${ }^{\circledR}$ Ankle Brachial Pressure Index (ABPI) (MESI, Ltd., Slovenia, EU) and pulse oximetry, such as Vismo ${ }^{\circledR}$ (Vismo, York, UK). First, we collected the demographics and comorbidity information of the patients. Afterward, we explained the informed consent act and obtained patient consent. Later on, we carried out a general clinical evaluation and performed the $\mathrm{ABI}$ and $\mathrm{SpO}_{2}$ measurements. This study was approved by the Institutional Review Board of the Hospital Universitario Hernando Moncaleano Perdomo de Neiva.

\section{Definitions}

Abnormal pulse oximetry was defined as $>2 \%=\mathrm{SpO}_{2}$ 's upper limb and $\mathrm{SpO}_{2}$ 's ipsilateral lower limb [13]. ABI categories were defined according to a measuring index. The reference measuring index is between $\geqslant 0.91$ and $<1.3$, an abnormal one is between $\geqslant 0.41$ and $<0.91$, a critical one is between $\geqslant 0$ and $<0.41$, and a subnormal one is $\geqslant 1.30[14]$.

\section{Statistical analysis}

Statistical analyses were performed using Stata ${ }^{\circledR}$, version 15 (StataCorp LLC, College Station, Texas, USA). A descriptive statistic was performed which made use of absolute $(\mathrm{N})$ and relative (\%) frequencies for categorical variables. For continuous variables, median (Med) and interquartile range (IQR) were employed. In order to compare $\mathrm{SpO}_{2}$ 's distribution, the Wilcoxon test was applied which showed a significant correlation of $\mathrm{p}$-value $<0.05$ between abnormal pulse oximetry and ABI. This correlation was assessed by using logistic regression with a 95\% confidence interval, a significant p-value $<0.05$, and the Pearson goodness-of-fit test post-estimation.

\section{Results}

From a total of 86 patients that were included in the study, 54 were male (62.8\%), and the median age was 54 years old (IQR: 37 - 65 yrs). The most frequent insurance type among patients was subsidized affiliation which covered 46 patients (54.5\%). The second most frequent insurance type was a contributive affiliation which covered 24 patients (27.9\%). The most frequent comorbidities were hypertension and diabetes (Table 1). Likewise, 23 patients (26.7\%) declared having a smoking habit in their case histories. Previous cases of outpatient medication involving beta-blockers, statins, and antiplatelet drugs showed low frequency (Table $1)$. 


\section{Cureus}

\begin{tabular}{|c|c|c|}
\hline \multirow[b]{2}{*}{ Age (years) ${ }^{\star}$} & \multicolumn{2}{|c|}{ Total n (\%) } \\
\hline & 54 & $(37-65)$ \\
\hline Male & 54 & (62.8) \\
\hline \multicolumn{3}{|l|}{ Insurance } \\
\hline Subsidized & 46 & (53.5) \\
\hline Contributive & 24 & (27.9) \\
\hline Special & 11 & (12.8) \\
\hline No coverage & 4 & (4.7) \\
\hline \multicolumn{3}{|l|}{ Comorbidities } \\
\hline Diabetes mellitus & 18 & (20.9) \\
\hline Smoking & 23 & (26.7) \\
\hline High blood pressure & 26 & (30.2) \\
\hline Stroke & 5 & (5.8) \\
\hline \multicolumn{3}{|l|}{ Premedication } \\
\hline Acetylsalicylic acid & 9 & (10.5) \\
\hline Beta-blockers & 4 & (4.7) \\
\hline Statins & 6 & $(7.0)$ \\
\hline
\end{tabular}

TABLE 1: Sociodemographic Characteristics of Patients Evaluated with ABI and SpO2

$\mathrm{ABI}$ : ankle-brachial index; $\mathrm{SpO}_{2}$ : peripheral capillary oxygen saturation

${ }^{*}$ Median (interquartile range)

In regard to the right lower limb (RLL) ABI measurements, a total of 66 patients (77.7\%) were classified in the reference category, while 20 patients $(22.3 \%$ ) were classified as abnormal. In regard to the ABI measurements of the left lower limb (LLL), a total of 67 patients (77.9\%) were classified in the reference category, whereas 21 patients (22.1\%) had an abnormal classification. The median $\mathrm{SpO}_{2}$ distribution of the RLL reference category was 96\% (IQR: 94\% - 97\%) and was 96\% in the LLL reference category (IQR: 94\% 97\%) (Figures 1-2). No statistical difference was found within the ABI categories (RLL: p-value $=0.2433$; LLL: $\mathrm{p}$-value $=0.1242$ ); this statistical comparison was not as significant as expected, despite comparing the reference group to non-reference measurements (RLL: $p$-value $=0.2126$; LLL: $\mathrm{p}$-value $=0.4293$ ). The $\mathrm{SpO}_{2}$ versus $\mathrm{ABI}$ and abnormal pulse oximetry in RLL were correctly classified in $76.7 \%$ and $77.9 \%$ in the LLL (Pearson's goodness-of-fit test RLL: p-value < 0.001 and LLL: p-value < 0.001) (Table 2). 


\section{Cureus}

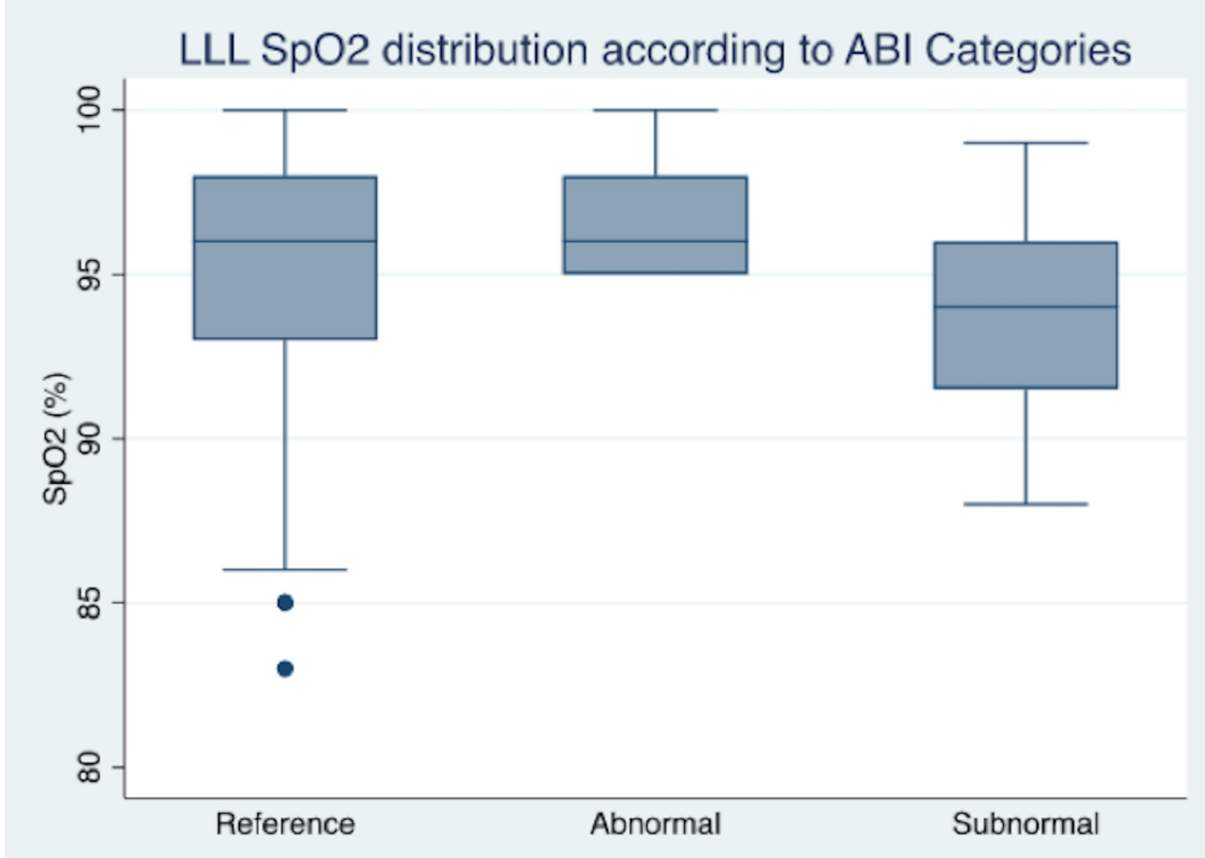

FIGURE 1: Graph box of SpO2 distribution according to LLL ABI reference of patients evaluated with $\mathrm{ABI}$ and $\mathrm{SpO} 2$

ABI: ankle-brachial index; LLL: left lower limb; $\mathrm{SpO}_{2}$ : peripheral capillary oxygen saturation

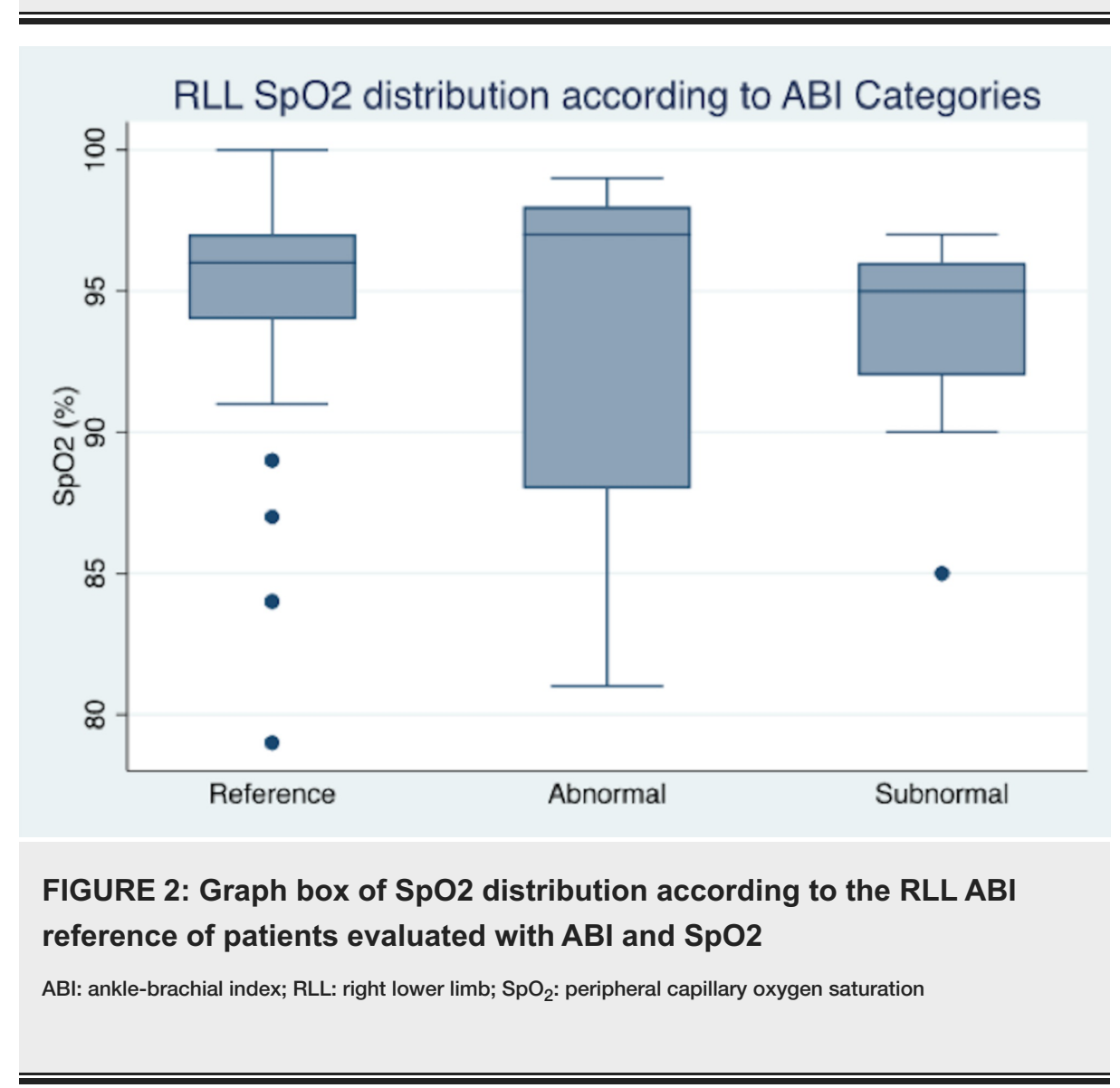




\begin{tabular}{|l|lll|l|l|l|l|l|}
\hline & $\mathbf{n}$ & $(\%)$ & Med (IQR) & p-value & n & $(\%)$ & Med (IQR) & p-value \\
\hline Reference & 66 & $(77.7)$ & $96(94-97)$ & 0.2433 & 67 & $(77.9)$ & $96(94-97)$ & 0.1242 \\
Abnormal & 6 & $(7.0)$ & $97(88-98)$ & & 7 & $(8.1)$ & $97(88-98)$ & \\
Critical &. &. &. &. &. &. \\
Subnormal & 14 & $(16.3)$ & $95(92-96)$ & & 12 & $(14.0)$ & $95(92-96)$ & \\
\hline
\end{tabular}

TABLE 2: SpO2 Distribution According to $A B I$ Reference of Patients Evaluated with $\mathrm{ABI}$ and SpO2

ABI: ankle-brachial index; IQR: interquartile range; Med: median; RLL: right lower limb; LLL: left lower limb; $\mathrm{SpO}_{2}$ : peripheral capillary oxygen saturation

\section{Discussion}

Patients with PAD have a higher functional impairment which may lead to amputations. Losing such clinical and functional life quality could turn out as an economic burden; in fact, it is often an under-recognized or underestimated entity during clinical practice [15-17]. In the literature, the most recommended noninvasive measure is ABI, which can be performed through Doppler and blood pressure readings [1-2]. In this standard practice, the patient is required to lay down in the supine position with his/her legs and heart horizontally (at the same height) so that the pulse rate of either the dorsalis pedis or tibial posterior artery can be checked. The higher systolic blood pressure (SBP) from the ankles is divided between the major SBP of the arm [18]. According to some studies, the ABI measurement has been recommended to be performed in asymptomatic patients between the ages of 50 to 65 years with PAD risk factors or clinical suspicion of it [7, 19]. In regards to our experience, most of the patients were younger than 65 years old and had a low atherosclerosis probability. This could also explain why there were no critical observations in ABI classifications [20-22]. Our study population consisted of patients mostly under the age of 65 years and patients who had subsidized insurance (this refers to people with unstable or no economic income).

Although we did not observe any statistical differences in $\mathrm{SpO}_{2}$ distribution measurements among $\mathrm{ABI}$ categories, the box plots showed a tendency towards a lower distribution within the non-reference classification. This result is more related to the specificity of $\mathrm{ABI}$ and $\mathrm{SpO}_{2}$ than it is to the sensitivity classification. According to the purpose of this study, claudication symptoms were not taken into account as they show asymptomatic patients who never had a PAD history. The observed $\mathrm{SpO}_{2}$ distribution behavior was consistent with the literature, which simultaneously added more information to this subject. The $\mathrm{SpO}_{2}$ measurement value was assessed with a $2 \%$ - 5\% difference; throughout our analysis, no statistical differences were found regarding finger-toe subtraction or the area under a curve near $60 \%$ with a nonsignificant goodness-of-fit test. This could elaborate more on the correlation between these findings; however, sample size hampers the analysis as described in other experiences [10-11, 13]. These results from the clinical setting may suggest that $\mathrm{SpO}_{2}$ can be a useful, non-invasive tool for assessing asymptomatic patients who are prone to PAD risk and have any blood pressure measuring contraindications. Our experience relays more data to this research line, and these findings are consistent with other experiences and relate to other invasive or treatment procedures [10-11, 13]. We also like to mention that additional to $\mathrm{SpO}_{2}$, the transcutaneous partial pressure of oxygen $\left(\mathrm{TcPO}_{2}\right)$ is another vascular tool commonly used in vascular medicine to reflect local arterial blood flow and skin oxygenation. This tool has been described as a potential predictor of cardiovascular events and blood flow before and after revascularization in patients with peripheral artery disease, including in patients with conditions such as end-stage renal disease and diabetes [23-25].

As was previously mentioned, this study is limited by sample size, which might affect the significance and performance of the statistical tests through factors, such as lacking critical patients classified according to $\mathrm{ABI}$. Furthermore, when interpreting these results, an explanation for the $\mathrm{SpO}_{2}$ correlation was uncovered. Another consideration for the interpretation of our results related to the performance of this correlation when classified as normal. This consideration is based on the heterogeneity recognition of categories that suggest the involvement of peripheral arterial disease and/or subnormal category when the ABI is $>1.3$. We believe that the correlation may vary under the conditions of low hemoglobin levels or other systemic perfusion alterations that might be heterogeneous in $\mathrm{SpO}_{2}$ distribution. The correlation assessment of both variables was evaluated with logistic regression as far as was feasible. We feel this assessment might contribute to the estimations to come regarding this issue. However, it should be noted that this can also act as a limitation to residual treatment due to the limited sample size. Similarly, as described in other experiences, we identified the need for doing further research regarding the relationship between $\mathrm{SpO}_{2}$ and 


\section{Conclusions}

Although we didn't observe any statistical differences in $\mathrm{SpO}_{2}$ distribution regarding $\mathrm{ABI}$ measurements, $\mathrm{SpO}_{2}$ can be a useful non-invasive tool to assess asymptomatic patients with risk factors for peripheral arterial disease $(\mathrm{PAD})$.

\section{Additional Information \\ Disclosures}

Human subjects: Consent was obtained by all participants in this study. Comite de Etica Bioetica E Investigación del Hospital Universitario Hernando Moncaleano Perdomo de Neiva issued approval 009-004. Animal subjects: All authors have confirmed that this study did not involve animal subjects or tissue. Conflicts of interest: In compliance with the ICMJE uniform disclosure form, all authors declare the following: Payment/services info: All authors have declared that no financial support was received from any organization for the submitted work. Financial relationships: All authors have declared that they have no financial relationships at present or within the previous three years with any organizations that might have an interest in the submitted work. Other relationships: All authors have declared that there are no other relationships or activities that could appear to have influenced the submitted work.

\section{Acknowledgements}

We would like to acknowledge all the people who helped us with this project, including those patients who participated. The authors declare that there is no conflict of interest regarding the publication of this paper nor did we have a funding resource for the project.

\section{References}

1. Xu D, Li J, Zou L, Xu Y, Hu D, Pagoto SL, Ma Y: Sensitivity and specificity of the ankle-brachial index to diagnose peripheral artery disease: A structured review. Vasc Med. 2010, 15:361-69. 10.1177/1358863X10378376

2. Páez AN, Oróstegui AM, Hernández HJ, Valencia LI, Reyes CI, Tapias LF, Orozco LC: Validation of oscillometric measurement of ankle-brachial index compared with arterial lower limb echo-doppler for arterial disease. Rev Colomb Cardiol. 2010, 17:157-66. 10.1016/S0120-5633(10)70235-7

3. Chaudru S, de Müllenheim PY, Le Faucheur A, Kaladji A, Jaquinandi V, Mahé G: Training to perform anklebrachial index: systematic review and perspectives to improve teaching and learning. Eur J Vasc Endovasc Surg. 2016, 51:240-47. 10.1016/j.ejvs.2015.09.005

4. Formosa C, Cassar K, Gatt A, et al.: Hidden dangers revealed by misdiagnosed peripheral arterial disease using ABPI measurement. Diabetes Res Clin Pract. 2013, 102:112-16. 10.1016/j.diabres.2013.10.006

5. Hiatt WR: Can measuring the ankle-brachial index improve public health?. J Am Coll Cardiol. 2008, 52:174344. 10.1016/j.jacc.2008.08.035

6. Unlu M, Yildirim AO, Demir M, Ozturk C, Celik T, Iyisoy A: Ankle-brachial index and cardiovascular outcome. Angiology. 2016, 67:193. 10.1177/0003319715599282

7. Caruana MF, Bradbury AW, Adam DJ: The validity, reliability, reproducibility and extended utility of ankle to brachial pressure index in current vascular surgical practice. Eur J Vasc Endovasc Surg. 2005, 29:443-51. 10.1016/j.ejvs.2005.01.015

8. Jubran A: Pulse oximetry. Crit Care. 2015, 19:272. 10.1186/s13054-015-0984-8

9. Kwon JN, Lee WB: Utility of digital pulse oximetry in the screening of lower extremity arterial disease . J Korean Surg Soc. 2012, 82:94-100. 10.4174/jkss.2012.82.2.94

10. Joyce WP, Walsh K, Gough DB, Gorey TF, Fitzpatrick JM: Pulse oximetry: a new non-invasive assessment of peripheral arterial occlusive disease. Br J Surg. 1990, 77:1115-17. 10.1002/bjs.1800771013

11. Jawahar D, Rachamalla HR, Rafalowski A, Ilkhani R, Bharathan T, Anandarao N: Pulse oximetry in the evaluation of peripheral vascular disease. Angiology. 1997, 48:721-24. 10.1177/000331979704800808

12. Ena J, Argente CR, González-Sánchez V, Algado N, Verdú G, Lozano T: Use of pocket pulse oximeters for detecting peripheral arterial disease in patients with diabetes mellitus. J Diabetes Mellit. 2013, 3:79-85. 10.4236/jdm.2013.32012

13. Parameswaran GI, Brand K, Dolan J: Pulse oximetry as a potential screening tool for lower extremity arterial disease in asymptomatic patients with diabetes mellitus. Arch Intern Med. 2005, 165:442-46. 10.1001/archinte.165.4.442

14. Lin JS, Olson CM, Johnson ES, Whitlock EP: The ankle-brachial index for peripheral artery disease screening and cardiovascular disease prediction among asymptomatic adults: a systematic evidence review for the U.S. Preventive Services Task Force. Ann Intern Med. 2013, 159:333-41. 10.7326/0003-4819-159-5-20130903000007

15. Swaminathan A, Vemulapalli S, Patel MR, Jones WS: Lower extremity amputation in peripheral artery disease: improving patient outcomes. Vasc Health Risk Manag. 2014, 10:417-24. 10.2147/VHRM.S50588

16. Dua A, Lee CJ: Epidemiology of peripheral arterial disease and critical limb ischemia . Tech Vasc Interv Radiol. 2016, 19:91-95. 10.1053/j.tvir.2016.04.001

17. Davies MG: Criticial limb ischemia: epidemiology. Methodist Debakey Cardiovasc J. 2012, 8:10-14

18. Jelinek HF, Austin M: The ankle-brachial index in clinical decision making . Foot. 2006, 16:153-57. 10.1016/j.foot.2006.04.003 


\section{Cureus}

19. Aboyans V, Criqui MH, Abraham P, et al.: Measurement and interpretation of the ankle-brachial index: a scientific statement from the American Heart Association. Circulation. 2012, 126:2890-909. 10.1161/CIR.0b013e318276fbcb

20. Taylor-Piliae RE, Fair JM, Varady AN, et al.: Ankle-brachial index screening in asymptomatic older adults. Am Heart J. 2011, 161:979-85. 10.1016/j.ahj.2011.02.003

21. Toma Y, Ishida A, Kinjo K, Ohya Y: Change in ankle-brachial index over time in a screened Japanese cohort The Okinawa Peripheral Arterial Disease Study. Circ J. 2016, 80:2004-2009. 10.1253/circj.CJ-16-0017

22. McDermott MM, Applegate WB, Bonds DE, et al.: Ankle-brachial index values, leg symptoms, and functional performance among community-dwelling older men and women in the lifestyle interventions and independence for elders study. J Am Heart Assoc. 2013, 2:e000257. 10.1161/JAHA.113.000257

23. Benhamou Y, Edet S, Begarin L, et al.: Transcutaneous oxymetry as predictive test of peripheral vascular revascularization in haemodialysis population. Nephrol Dial Transplant. 2012, 27:2066-69.

10.1093/ndt/gfr564

24. Byrne P, Provan JL, Ameli FM, Jones DP: The use of transcutaneous oxygen tension measurements in the diagnosis of peripheral vascular insufficiency. Ann Surg. 1984, 200:159-65. 10.1097/00000658-19840800000007

25. Salman M, Glantzounis GK, Yang W, Myint F, Hamilton G, Seifalian AM: Measurement of critical lower limb tissue hypoxia by coupling chemical and optical techniques. Clin Sci (Lond). 2005, 108:159-65.

10.1042/CS20040175 